\title{
Prevalence of PUFA Rich Thraustochytrids sps. along the Coast of Mumbai for Production of Bio Oil
}

\author{
Aparna Pandey, Zarine Bhathena* \\ Dept of Microbiology, Bhavans College, Mumbai 58, INDIA \\ *Corresponding author: zarine_bhathena@rediffmail.com
}

Received September 01, 2014; Revised November 17, 2014; Accepted November 27, 2014

\begin{abstract}
Aims: To obtain axenic cultures of Thraustochytrids and assess the diversity of Thraustochytrids spps within the mangrove regions of Mumbai for their ability to produce DHA. Methods and Results: Samples obtained from various mangrove regions in and around the Mumbai coastline were screened for presence of Thraustochytrids cultures. Modified procedures involving use of various media and antibiotic treatment regimes were formulated to obtain axenic cultures of Thraustochytrids. Though $40 \%$ of the samples under study showed presence of pollen baitable Thraustochytrids, only 5\% of these spps could be recovered through direct isolation techniques on the conventional penicillin streptomycin B1 agar plate. In contrast, use of antibiotic cocktail during baiting lead to better recovery such that $57.14 \%$ of all the positive pollen baited samples were able to be recovered as axenic isolates on isolation on antibiotic laden B1 agar. For most of the isolates the fatty acid profile range between 60 to $76 \%$ of their dry cell mass; with total fatty acid content of $5.92 \pm 0.41 \mathrm{~g} \mathrm{~L}^{-1}$ of which $1.97 \pm 0.08 \mathrm{~g} \mathrm{~L}^{-1}$ was DHA. Conclusion: Though marine mangrove environments are known habitat of Thraustochytrids its axenic cultivation is a challenge especially as the profile of contaminating bacteria and fungi within polluted areas varies from that within pristine locales. Removal of bacteria and fungi from an environment loaded with an higher organic load required mixture of three antibiotics and one antifungal; rifampicin (300 $\left.\mathrm{mg} \mathrm{l}^{-1}\right)$, streptomycin/penicillin $\left(25 \mathrm{mg} \mathrm{l}^{-1}\right)$ and nystatin $(10 \mathrm{mg}$ $\mathrm{I}^{-1}$ ) to be incorporated in seawater samples for a minimum of 2 days so that Thraustochytrids could be selectively isolated from the Indian Mangrove region,. Significance and Impact of Study: This data represents the first extensive study on the prevalence of Thraustochytrids across the coast of Mumbai and the combination of antibiotics that need to be used for its effective recovery.
\end{abstract}

Keywords: thraustochytrids, screening, antibiotics, fatty acids, DHA

Cite This Article: Aparna Pandey, and Zarine Bhathena, "Prevalence of PUFA Rich Thraustochytrids sps. along the Coast of Mumbai for Production of Bio Oil." Journal of Food and Nutrition Research, vol. 2, no. 12 (2014): 993-999. doi: 10.12691/jfnr-2-12-21.

\section{Introduction}

Long chain polyunsaturated fatty acids (LC-PUFAs) such as eicosapentaenoic acid (EPA, C20:5n-3) and docosahexaenoic acid (DHA, C22:6n-3) are recognized as beneficial elements in both nutrition and pharmacology (Dratz and Deese, 1986) and are recommended as food additive. DHA have proven beneficial in the prevention of cardiovascular diseases, cancers, arthritis and Alzheimer's disease (Horrocks LA, 1999). Omega-3 fatty acids and in particular, DHA plays an important role in infant brain and retinal development and thus need to be added to the diet in order to maintain the physical and mental abilities. In fact, the American Dietetic Association and Dieticians of Canada officially recommend that 20 to $35 \%$ of daily energy should come from dietary fat, with an emphasis on consuming omega-3 fatty acids (Kris-Etherton and Innis, 2007). Though routinely extracted from oily fishes such as salmon and sardine, an alternative to this depleting supply source needs to be addressed as, The Food and Agriculture Organization of the UN predicts that global fish oil demand in 2015 will be $145 \%$ of historical global production capacity and will only continue to grow.

Though autotrophic microbes have been assessed for its potential as commercial sources of EPA and DHA by various workers (Carvalho and Malcata, 2005; Bhosale, R.A et al, 2010), it is doubtful whether the growth of microalgae in photo bioreactors could be scaled up to satisfy even a modest demand for Single Cell Oil rich in $n-3$ PUFA; mandating the use of heterotrophic nutrition as a more productive mode of algal growth.

Though the unicellular eukaryotic marine protists family of Thraustochytrids, includes the genera of Aurantiochytrium, Parietichytrium, Schizochytrium and Thraustochytrium. Thraustochytrids are thought to be far superior in the production and accumulation of PUFAs, as they accumulate large amounts of DHA and n-6 docosapentaenoic acid (C22:5n-6) with little cross contamination with EPA or arachidonic acid (C20:4n-6) (Nakahara et al 1996; and Yaguchi et al 1997) due to their ability to produce PUFA synthase that supplements the standard pathway for fatty acid/squalene production.

Though Thraustochytrids generally represent a negligible fraction of microbial abundance and a minor 
fraction of the total benthic microbial biomass, they are ubiquitous in marine and estuarine environments, in both tropical and sub-tropical areas. They are reported to be associated with mangrove swamps, oceanic water (Raghukumar 2002), marine sediment where they play an important role in promoting carbon turn over (Bongiorini et al 2004) using their system of hydrolytic enzymes within their ectoplasmic net (EN) elements that contributes to the increased surface area enabling digestion of organic material (Raghukumar, 2002).

Despite the seeming environmental and economic importance of these species, to date no studies have been reported on the Thraustochytrids obtained from Mumbai. The Mumbai coast line though endowed with extensive mangrove regions is a sink for the Mithi river that empties its organic load collected as it criss crosses the Mumbai slum areas creating a need to evaluate techniques for axenic Thraustochytrid isolation and culture. Though methods like repeated dilutions with or without antibiotics have been used, (Pine pollen MPN method) treatment with antibiotics is the most common method used for the removal of bacteria and fungi though it rarely yields a culture free of contaminants. Thus no single procedure or antibiotic is thus likely to successfully support an axenic culture, especially if the sample is taken from environments that have high load of other fast growing heterotrophic microorganisms. Additionally, the use of a multitude of antibiotics may have deleterious and stressful effect on the algae preventing its recovery. Thus, a judicious use of antibacterial agents along with the use of right medium that would allow the cultivation of Thraustochytrids besides preventing overgrowth of bacteria and fungi would help to obtain axenic strains that can be used to assess their biotechnological potential

This study therefore aims at studying the profile of Mangroves in Mumbai with respect to its presence of various Thraustochytrid like strains using various antibiotic concoction for isolation of axenic Thraustochytrid like organisms and assess their ability to produce DHA.

\section{Materials and Methods}

\subsection{Screening}

Isolation of Thraustochytrids, a detritus feeder and an exclusive marine inhabitant was undertaken from samples of estuarine water, decaying mangrove leaves (Leano, 2003), soil and pneumatophores (Raghukumar, 2002) collected in the year 2012 from various mangrove areas of Mumbai (Figure 1) and Goa. The samples were placed in a petri dish containing $5 \mathrm{ml}$ of artificial sea water (ASW) dusted with pine pollen so as to bait Thraustochytrid spps. The enrichment plates containing ASW and pine pollen were incubated at $20^{\circ} \mathrm{C}$ for 7 days under continuous light conditions. The plates were examined under low power and high power on day 4, 5, 6 and 7 for colonised pollen grain. Once Thraustochytrid had colonised the pollen, 10 ul was loaded on heamotocytometer to determine the numbers of Thraustochytrid adhering to the pollens while the ability to be isolated into colony forming units was determined by plating $10 \mathrm{ul}$ on B1 agar plates.

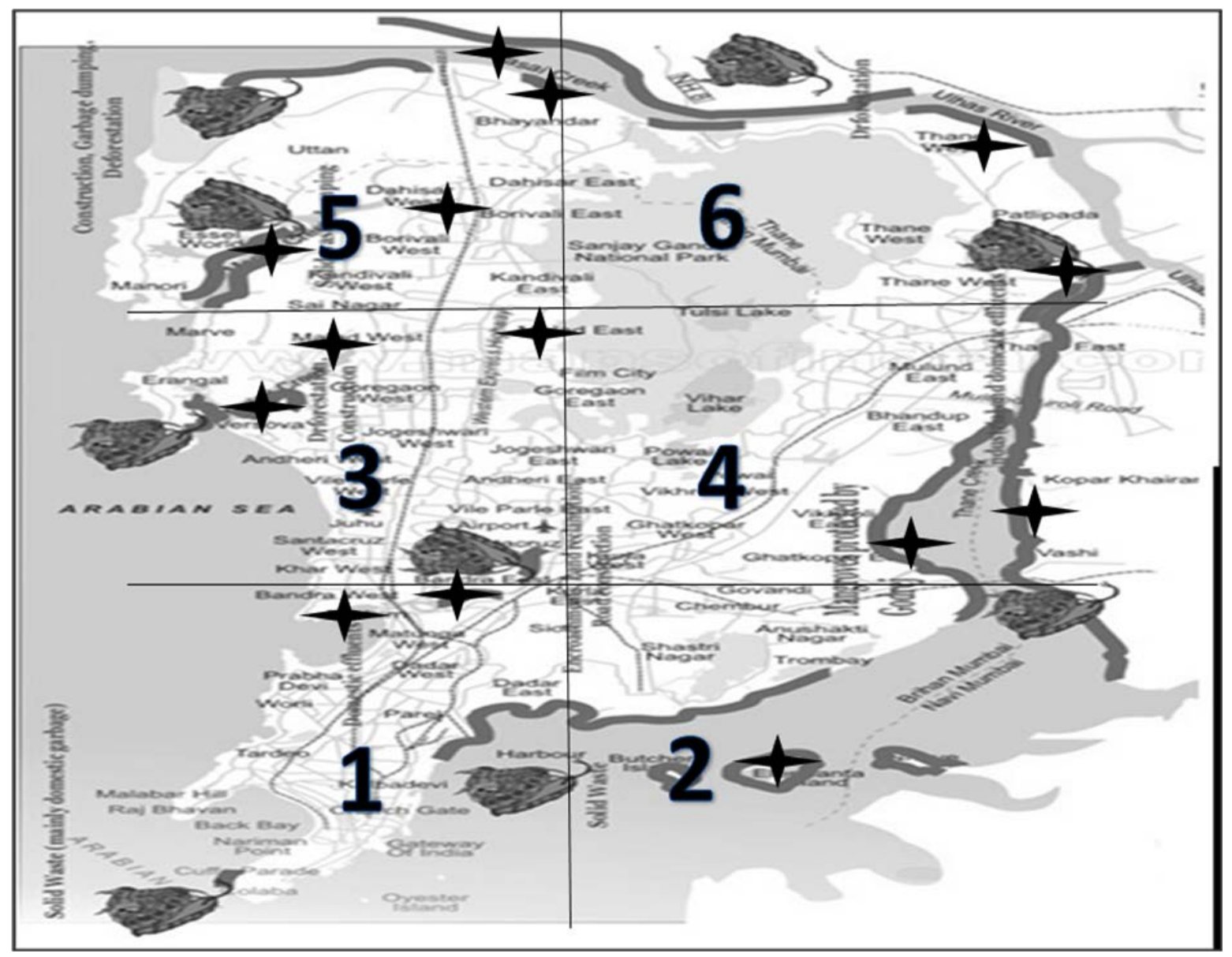

Figure 1. Location of mangrove region around Mumbai coast (Courtesy: http://www.mangroves.godrej.com/MangrovesinMumbai.htm) 


\subsection{Antibiotic trails}

Seven non axenic stock cultures were prepared for each of the antibiotic treatment (Table 1 ) by transferring $1 \mathrm{ml}$ of Positive pollen baited samples into $100 \mathrm{ml}$ of SCW broth containing various combinations of antibiotic. The flasks were incubated for a period of 1 day and increase in the presence of Thraustochytrid colonies detected by plating 10 ul of treated samples on similar isolation media. The plates were incubated for 3 days at $28^{\circ} \mathrm{C}$ before visual inspection for presence of bacteria and fungi. Presence of Thraustochytrid colonies was visually confirmed by light microscopy as well as by wet mount besides confirming the presence of Thraustochytrids.

Table 1. Antibiotic treatment used for recovery of Thraustochytrid colonies from Mangrove Sammple

\begin{tabular}{|c|c|c|c|c|c|c|c|c|c|c|}
\hline \multirow[b]{2}{*}{$\begin{array}{c}\text { Isolatio } \\
\text { n set }\end{array}$} & \multirow[b]{2}{*}{$\begin{array}{l}\text { Basal } \\
\text { agar }\end{array}$} & \multicolumn{9}{|c|}{ Antibiotics added within the basal medium } \\
\hline & & $\begin{array}{l}\text { Penicilli } \\
\text { n (mg L- } \\
1)\end{array}$ & $\begin{array}{c}\text { Streptomyci } \\
\text { n }\left(\mathrm{mgL}^{-1}\right)\end{array}$ & $\begin{array}{l}\text { Ampicilli } \\
\mathrm{n}\left(\mathrm{mg} \mathrm{L}^{-1}\right)\end{array}$ & $\begin{array}{l}\text { Tetracycli } \\
\mathrm{n}\left(\mathrm{mg} \mathrm{L}^{-1}\right)\end{array}$ & $\begin{array}{l}\text { Fluconazol } \\
\text { e (mcg mL- } \\
1 \text { ) }\end{array}$ & $\begin{array}{c}\text { Rifampici } \\
\mathrm{n} \\
\left(\mathrm{mg} \mathrm{L}^{-1}\right)\end{array}$ & $\begin{array}{c}\text { Chloramphenico } \\
\text { l } \\
\left(\mathrm{g} \mathrm{L}^{-1}\right)\end{array}$ & $\begin{array}{c}\text { Kanamyci } \\
\mathrm{n}\left(\mathrm{g} \mathrm{L}^{-1}\right)\end{array}$ & $\begin{array}{c}\text { Contro } \\
1\end{array}$ \\
\hline 1 & B1 & 300 & 500 & - & - & - & - & - & - & - \\
\hline 2 & SWC & - & - & 20 & 2 & 100 & - & - & - & - \\
\hline 3 & SWC & - & - & - & - & 100 & 25 & - & - & - \\
\hline 4 & $\begin{array}{l}\text { SWC } \\
\text { Mar }\end{array}$ & 300 & 500 & 20 & 2 & 100 & 25 & - & - & - \\
\hline 5 & $\begin{array}{l}\text { Chiquita } \\
\text { agar } \\
\text { Mar }\end{array}$ & 300 & 500 & - & 0.1 & - & - & 0.1 & 0.1 & - \\
\hline 6 & $\begin{array}{l}\text { Chiquita } \\
\text {-BHI } \\
\text { agar }\end{array}$ & 300 & 500 & - & 0.1 & - & - & 0.1 & 0.1 & - \\
\hline 7 & SWC & 300 & 500 & 20 & 2 & 100 & 25 & - & - & \\
\hline
\end{tabular}

Shortlisting the use of SWC and Mar Chiquita medium was based on its ability not to affect Thraustochytrid cell growth of three representative pure strains obtained from the Indian coast (data not shown).

\subsection{Fluorescent Staining for Qualitative Lipid Analysis}

Preliminary analysis for detection of intracellular lipids within the recovered Thraustochytrid strains was undertaken using Nile red lipid staining technique wherein $2 \mathrm{~mL}$ aliquot of isolate was mixed with $20 \mu \mathrm{L}$ of Nile Red solution (0.05 mg mL $\mathrm{m}^{-1}$ ), vortexed for $1 \mathrm{~min}$ and incubated for $5 \mathrm{~min}$ at room temperature in dark. Fluorescence of Nile red was visualized using Axio Scope. A1 microscope, at $490 \mathrm{~nm}$ and $525 \mathrm{~nm}$ excitation and emission wavelength respectively. The stained cells were observed for yellow orange fluorescence of lipid granules within the cytoplasm (Bertozzini 2011).

\subsection{Inoculum Preparation}

A single colony of 48 hour old isolates grown on B1 agar was inoculated into $50 \mathrm{ml} \mathrm{B1}$ broth, and incubated at $28^{\circ} \mathrm{C}$ at $120 \mathrm{rpm}$ for 48 hours to be used as $2 \%$ inoculum. The inoculated media was incubated at $28^{\circ} \mathrm{C}$ at $120 \mathrm{rpm}$ for 96 hours.

\subsection{Dry Cell Weight Determination}

Dry cell weight (DCW) was estimated by harvesting cells at $5400 \mathrm{~g}$ at $4^{\circ} \mathrm{C}$ for $20 \mathrm{~min}$. The pellet was washed thrice with phosphate-buffered saline (PBS, $\mathrm{pH}$ 7.2) and the cells thus obtained was vortexed in $600 \mu \mathrm{l}$ of distilled water dispensed in a pre-weighed vial. The vials were then dried overnight at $90^{\circ} \mathrm{C}$ or till a constant weight was obtained.

Isolates that did not settle upon centrifugation at $5400 \mathrm{~g}$ at $4^{\circ} \mathrm{C}$ for $20 \mathrm{~min}$ were passed through a preweighed filter of $1 \mu$ pore size. The culture thus obtained on the filter was washed with Phosphate buffer $\mathrm{pH} 7.4$ and dried at $90^{\circ} \mathrm{C}$ overnight in a hot air oven and weighed.

\subsection{Lipid Analysis by Gravimetric Method}

Total lipid content was calculated using a modified miniaturized Bligh-Dyer method (Burja, 2007) where in $125 \mathrm{mg}$ of dried cells were mixed with $6.25 \mathrm{ml}$ chloroform, $12.5 \mathrm{ml}$ methanol, and $5 \mathrm{ml}$ of $50 \mathrm{mM} \mathrm{K} \mathrm{HPO}_{4}$ buffer solution ( $\mathrm{pH}$ 7.4). Samples were agitated for $1 \mathrm{~h}$, at 200 $\mathrm{rpm}$, at $28^{\circ} \mathrm{C}$, after which further $6.25 \mathrm{ml}$ chloroform 12.5 $\mathrm{ml}$ methanol and $6.25 \mathrm{ml}$ phosphate buffer was added to each sample. The liquid was then transferred to a $60 \mathrm{ml}$ separating funnel, mixed well and allowed to settle for 1 hour. The bottom organic layer was then transferred to a pre-weighed aluminium dish and the solvent allowed to evaporate for $30 \mathrm{~min}$ in a hot air oven set at $80^{\circ} \mathrm{C}$. The contents were then weighed after cooling the dish, and total lipid levels determined gravimetrically using the following equation:

Total lipid ( $\mathrm{g}$ of oil/ $100 \mathrm{~g}$ sample) $=\left(\mathrm{W}_{\mathrm{L}^{-}}\right.$ $\left.\mathrm{W}_{\mathrm{D}}\right) \times \mathrm{V}_{\mathrm{C}} \times 100 /\left[\mathrm{V}_{\mathrm{P}} \times \mathrm{W}_{\mathrm{S}}\right]$

Where, $W_{D}$ was the weight of an empty aluminium dish (g); $\mathrm{W}_{\mathrm{L}}$ the weight of an aluminium dish with dried lipid residue $(\mathrm{g})$; $\mathrm{W}_{\mathrm{S}}$ the weight of sample $(\mathrm{g}) ; \mathrm{V}_{\mathrm{C}}$ the total volume of chloroform in the graduated cylinder $(\mathrm{mL})$; and $\mathrm{V}_{\mathrm{P}}$ the volume of chloroform transferred to the aluminium dish (mL).

\subsection{Glc Analysis for Fatty Acid}

$125 \mathrm{mg}$ of harvested dried cells were resuspended in 3 $\mathrm{ml}$ of $5 \%(\mathrm{v} / \mathrm{v})$ methanolic sulfuric acid and Nitrogen gas flushed in the vials for $30-60 \mathrm{sec}$. The samples were then heated at $90^{\circ} \mathrm{C}$ for $1 \mathrm{~h}$ in sealed vials. Fatty acid methyl esters (FAMEs) were then extracted into $0.6 \mathrm{ml}$ hexane and analyzed by gas chromatography (GC; Hewlett Packard 6890N) using Nitrogen as a carrier gas(Hong et al, 2011). The instrument was equipped with a flameionization detector (FID) and an SP 2300 column having length of $2 \mathrm{~m}$ and internal diameter of $2 \mathrm{~mm}$. The column temperature was raised from $150^{\circ} \mathrm{C}$ (after 2 min of holding) to $220^{\circ} \mathrm{C}$ (with a further 2 min of holding) at a 
rate of $5^{\circ} \mathrm{C}$ per min. The temperature of injection port was $220^{\circ} \mathrm{C}$ while that of the detector was used at $230^{\circ} \mathrm{C}$.

\section{Results}

\subsection{Screening}

Mumbai is a coastal city crisscrossed with creeks and estuarine that creates substantial mangrove areas. Most of the mangrove areas lack the pristine characteristics as it is closely associated with the local population and thus the collected samples carried a heavy contamination of organic matter. As a matter of convenience the city was divided into 6 zones (Figure 1) and sampling systematically carried out from each of the zone such that a total of 20 sites yielding 280 samples comprising of water, decayed leaves, soil and pneumatophores were examined. Screening for Thraustochytrids using pollen bait technique performed using samples from Bhandup creek, Malad creek, Mahim creek, Aksa beach, Bhati village beach, Panvel creek, Vashi creek, Ghodbunder creek, and Elephanta bay failed in obtaining any
Thraustochytrids. However samples from comparative cleaner areas like Versova creek, Vikhroli creek, Gorai creek, Bhayender creek, Mira road creek, Vasai creek, Bandra creek, Thane creek, Chorao forest and mangrove areas of Panjim showed presence of Thraustochytrids such that isolates adhering to pollen could be obtained. Direct microscopic count of $10 \mu \mathrm{l}$ of various samples baited ASW + pine pollen loaded on haemocytometer revealed presence of total 58 adsorbed Thraustochytrid isolates, of which only 32 isolates could be recovered as colonies on B1 agar (Figure 2). Such poor recovery of Thraustochytrid colonies on solid medium could be due to unique nutritional requirement of the Indian strains, thus screening of various isolation media was undertaken in order assess nutrient requirements of the isolates. In spite of six different isolation media being used all the remaining $43 \%$ isolates failed to form colonies indicating that these isolates had unique nutritional requirements that could not be provided by the isolation media and they remained in association with pine pollen unable to form any colonies even after 3 weeks of incubation.

Table 2. Effectiveness of antibiotic combinations for Thraustochytrid purification

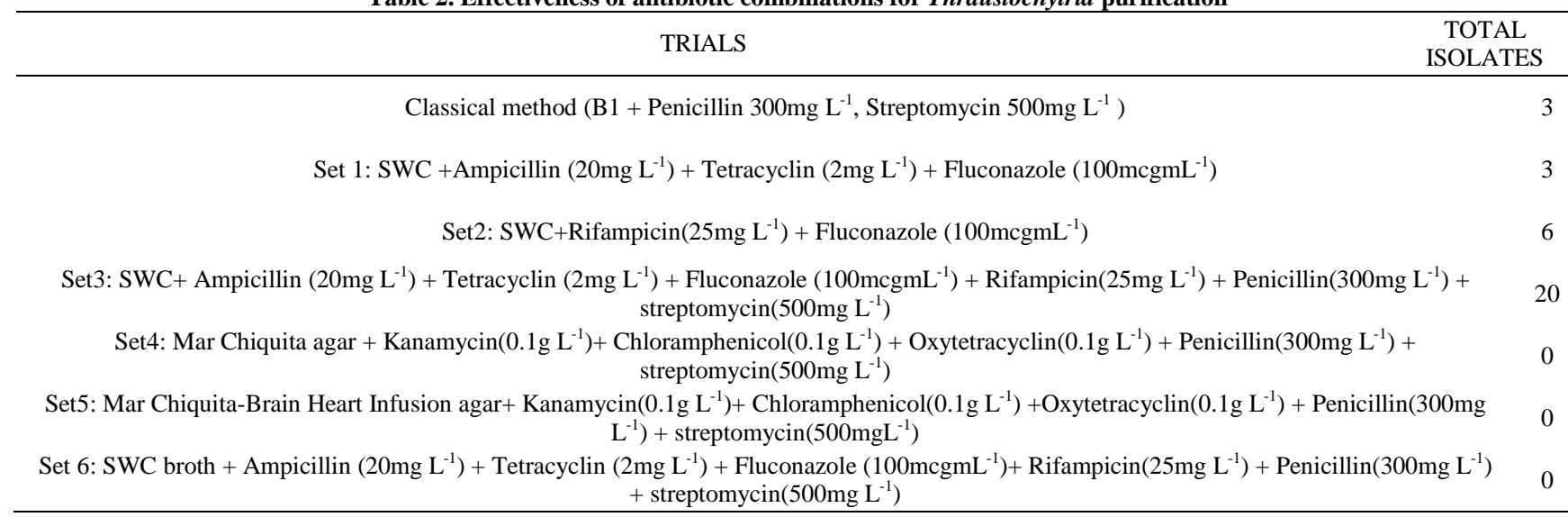

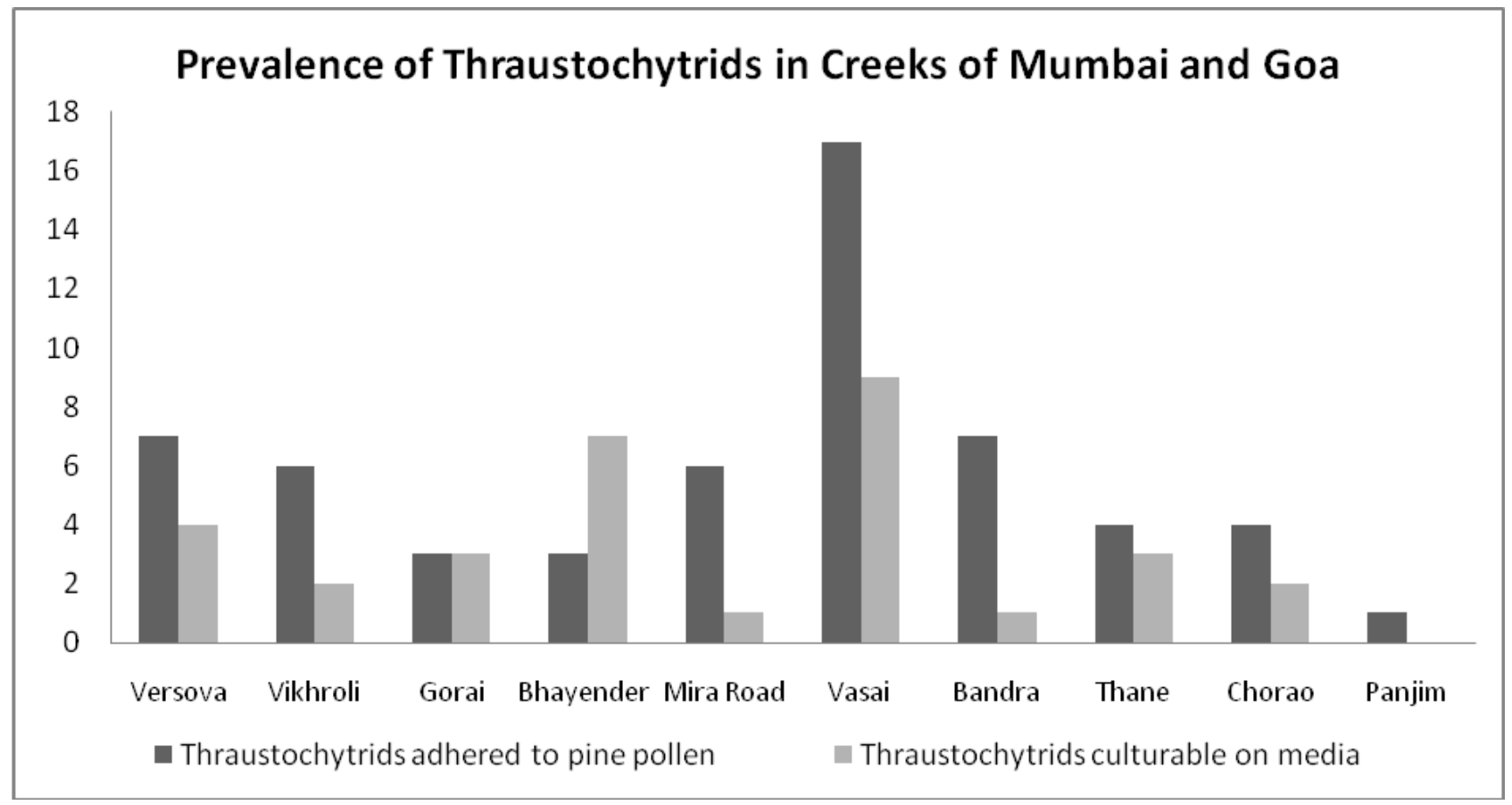

Figure 2. Prevalence of Thraustochytrids isolates in mangrove regions of Mumbai (Courtesy: http://www.mangroves.godrej.com/MangrovesinMumbai.htm) 
Percentage prevalence of Thraustochytrids in various sample types

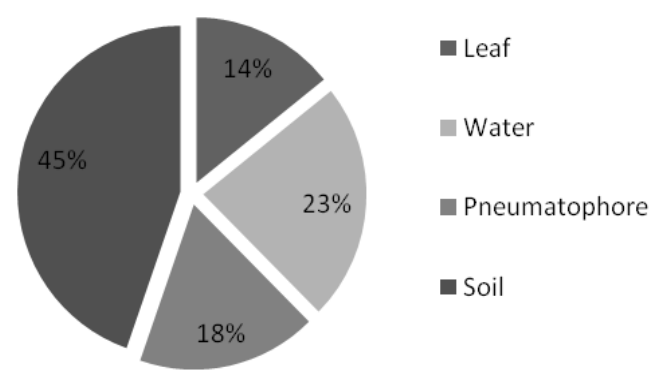

Figure 3. Recovery of Thraustochytrids from various samples analysed

All the 32 recovered colonies obtained were highly contaminated with bacteria and fungi such that even on isolation on conventional B1 media supplemented with the traditionally used penicillin and streptomycin antibiotic it yielded colonies of contaminants within the range of $10^{3}$ to $10^{4} \mathrm{cfu} \mathrm{mL}^{-1}$ that overshadowed the detection of Thraustochytrids. Thus using SWC as a base medium; antibiotic treatments trails that could effectively reduce bacterial and fungal contaminants was set up, the results of which are shown in Table 2.

Of the variety of samples analyzed soil sediment proved to be most abundant niche as $60 \%$ of soil samples showed presence of Thraustochytrids (Figure 3).

Comparison of the various antibiotic combinations (Table 2) used within the isolation medium for their purification indicated that use of chloramphenicol or Oxytetracycline was not a good choice as it ability to inhibit 50S ribosome activity provided selective pressure that allowed yeast and fungi to dominate. In contrast, use of traditional bacteriostatic antibiotic like penicillin and streptomycin along with Ampicillin and Rifampicin through their various varied mode of action were able to inhibit a wider range of fast growing bacteria and thus provide a window for the slow growing Thraustochytrids to grow without being overwhelmed by the fast growing bacterial and yeast strains. Additionally, the antifungal activity provided through the use of fluconazole created an antibiotic cocktail (set 3) that could allow growth and purification of $62.5 \%(20 / 32)$ isolates. This is in contrast to the use of the traditional penicillin and streptomycin mixture or Ampicillin, tetracycline, fluconazole mixture that purified only 9.3\% (3/32) isolates. Use of Rifampicin a broad spectrum bactericidal antibiotic along with antifungal agent fluconazole was found to be intermediately effective as it could allow growth and purification of $18.75 \%$ (6/32) isolates but may not find application due to its high cost.

\subsection{Dcw Lipid and Fame Analysis}

From the pure 32 isolates further, selection of potent oleaginous strains was assessed using Nile red lipid staining technique for detection of lipid granules as yellow orange fluorescent granules over a period of 96 hrs. Many of the isolate recovered varied in their growth rate such that out of the 32 isolates, only 15 isolates could form good large colonies on B1 agar within 48-72 hours. Thus these isolates were therefore further selected for GC PUFA profiling, biomass productivity, maximal TFA, and DHA (Figure 4 and Figure 5). Isolates having faster growth rate were examined for their potential to produce omega 3 fatty acids and all strains showed presence of DHA. GW11 showed highest DHA of $1.97 \mathrm{~g} \mathrm{~L}^{-1}$ of under unoptimized condition.

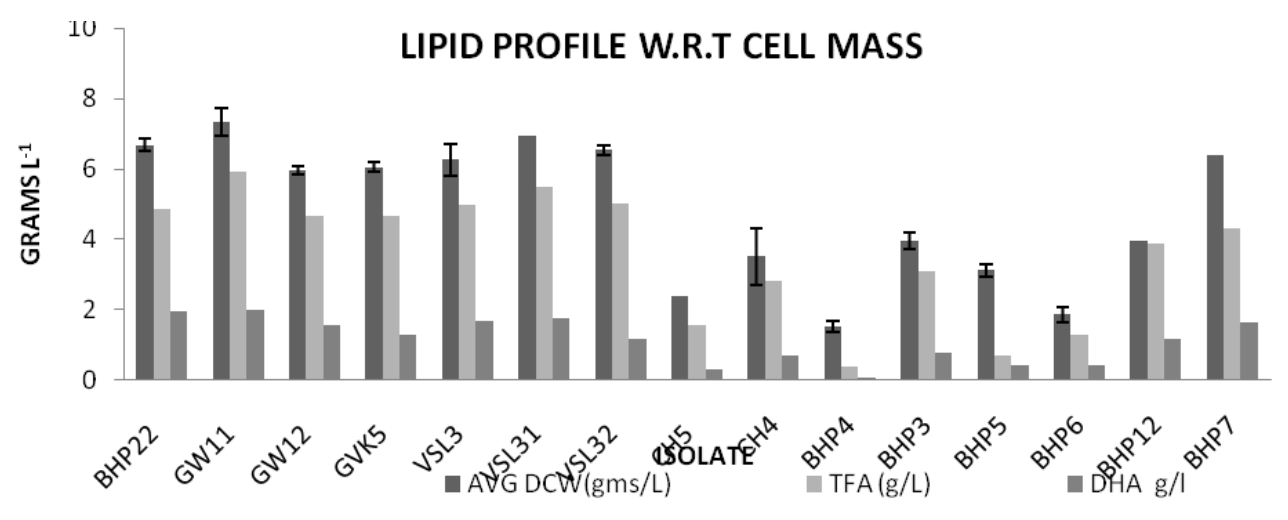

Figure 4. Lipid profile of Isolates with respect to cell mass

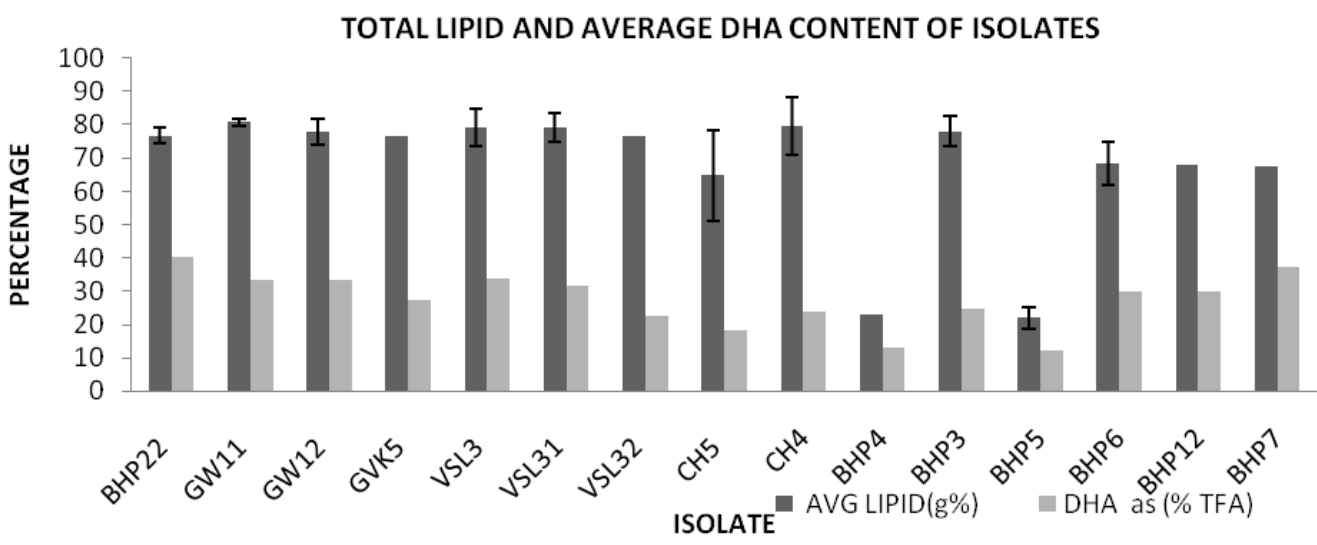

Figure 5. Lipid profile of Isolates with respect to DHA 


\section{Discussion}

Large scale culture of Thraustochytrids has potential to be developed as a commercial source of PUFA and other important products such as antioxidants, pigments, (Aki et al., 2003) polysaccharides (Jain, R. and Raghukumar 2005) etc. Thus though they represent a potentially competitive player in the PUFA market, considerable work is required before production of oil from these organisms significantly increases its share of the market for PUFA rich products. To achieve this aim a reliable collection and isolation protocol for PUFA rich strains needs to be established. Though protocols are available for cultivation of axenic cultures of these microalgae many a times it fails as the indigenous flora from where the sample is collected is unique and require its own set of selective pressures that need to be used to enable successful recovery of these strains.

Here we present a reliable method to obtain axenic cultures of Thraustochytrids from the tropical coastal areas of Mumbai, a preliminary step in the development of biotechnology of Indian Thraustochytrids.

Based on the prevalence data and the recovery results Indian Thraustochytrid spps were not ubiquitously distributed within mangrove regions. While considering the location of the sampling sites, one common observation was that most mangrove areas (except Chorao forest, Bhayender and Vikhroli samples) were associated in some way with proximity of human residence and the samples had heavy contamination of organic matter. Concomitantly these samples that had high organic load showed absence of any strain of Thraustochytrids such that 10 samples were completely devoid of their presence. Additionally pine pollen baiting method was found to be conducive for enrichment of Thraustochytrids such that $37 \%$ of the baited samples showed presence of Thraustochytrids adhered to pollen. However of which $55 \%$ showed very slow growth rate. Isolates were confirmed as Thraustochytrid like organism based on microscopic examination of the colony formed on agar surface and lipid staining by Nile red which confirmed the isolates obtained were high in their lipid content.

The morphological characterization of the isolates along the Indian West coast showed unique biodiversity. $27 \%$ of the isolates showed orange pigmentation, which could be carotenoids since these pigments are synthesized by oil rich organisms in order to inhibit oxidation of cellular lipids (Aki T, 2003). One common observation was that the isolates showing pigmentation had slower growth rate. Comparison of pigmented (8 strains) with non pigmented strains showed non pigmented strains had higher cell mass and total fatty acids and therefore posses higher DHA content. Thus non pigmented candidates could be better candidates for DHA production. (Fan, K. $\mathrm{W}$, et al 2009) However pigmented strains could be considered for their dual property of producing pigments and PUFAs.

Isolates that showed slow growth rate had short life span of less than one month on $0.8 \%$ B1 agar (Glucose $1 \%$, yeast extract $1 \%$ and Sea water $70 \%$ ) on solid medium. In order to maintain them viable frequent subculture was required. Additionally, area wise distribution profiling indicated that locations such as Bhayender creek and Gorai were rich in fast growing strains, with most of the strains morphologically resembling Aurantochytrium genera. Vasai mangrove area profiled very high number and wide variety of Thraustochytrid like isolates and along with slow growers and pigmented strains it also showed presence of fast growers.

Since the samples were from area used by human population organic load was added through human faecal matter and thus there were high chances of contaminants that were antibiotic resistant therefore complex concoction of antibiotics was an important factor to be standardized if axenic recovery of Thraustochytrid isolates was to be undertaken. Also many Thraustochytrids are slow growers, and overgrowth of bacteria along with yeast was a common problem, such that in many plating a ratio of 1 Thraustochytrid colony surrounded by 50-60 contaminants were observed making it a magnimous task to select the right colony. Thus, perfect consortia of antibiotics needed to be formulated for successful isolation of Thraustochytrids. Penicillin $300 \mathrm{mg} \mathrm{L}^{-1}$ and streptomycin $500 \mathrm{mg} \mathrm{L}^{-1}$ was effective in discouraging bacterial contamination, but mold proliferation increased due to reduced bacterial competition, thereby necessitating the need for adding antifungal agent. This finding was also supported by set 4 and set 5 concoctions where antifungal agents were not used.

Though various use of various antifungal agents such as Amphotericin B and nyastatin are reported. Use of Amphotericin B inhibited Indian Thraustochytrids as opposed to findings of Taoka Y et al, 2010. This was proved when pure strains of Indian Thraustochytrid was grown in presence of Amphotericin $\mathrm{B}\left(1 \mu \mathrm{g} \mathrm{mL}^{-1}\right)$ no growth was observed even after seven days of incubation while control set with B1 medium without amphotericin B showed visible colonies within 48 hours. This finding indicates that not all strains of Thraustochytrids can withstand action of antifungal agent Amphotericin B. Another antifungal Nyastatin $\left(10 \mathrm{mg} \mathrm{L}^{-1}\right)$ tested as per Wilkens, 2011, was found to be inefficient in controlling the contamination of yeast and mold during the course of enrichment may be due to the heavy contaminant load. Fluconazole (100 $\left.\mathrm{g} \mathrm{m} \mathrm{ml}^{-1}\right)$ along with other antibacterials, on the other hand was found to be effective in controlling growth of yeast and molds. Thus perfect consortia of antibacterial and antifungal agent once standardised would prevent imbalance that would allow excessive proliferation of the other group and this is the first report that recommends use of Fluconazole $\left(100 \mu \mathrm{g} \mathrm{mL}^{-1}\right)$ as an antifungal for selective isolation of Indian Thraustochytrids spps.

Additionally as observed in the above result set 1 and set 2, selective pressure of antibiotic allowed enrichment of Thraustochytrids that were primarily fast growers and could form large colonies within 48 hours. This indicates that this consortium can select Thraustochytrids having faster growth rate. In contrast use of set 3 antibiotic consortium allowed recovery of wide range of axenic Thraustochytrids though many of which were slow growers and require more than seven days to form colonies. However since the load of antibiotics in this consortium is high it should be used only for samples that have very high rate of bacterial and fungal competition. 
Considering the importance of fast growing isolates at industrial scale they were analyzed for their total lipids and DHA content. Lipid analysis showed that the isolates could accumulate lipids upto $80 \%$ of their cell mass which is higher than any reported value to our knowledge. Dry cell weight of the local isolates in an unoptimized medium ranged from 4-7 $\mathrm{g} \mathrm{L}^{-1}$ for the fast growing strains, thus optimizing medium to increase their dry cell weight could yield higher DHA.

GC-FID data showed all these isolates showed presence of signature PUFA profile of Thraustochytrids, which further authenticates the morphological identification of the local isolates. Quantification of DHA by GC-FID shows that the Thraustochytrids isolated from mangrove areas of Mumbai show presence of potent isolates with ability to produce high amount of DHA even under unoptimized conditions. Total lipid content of all the isolates under study (except CH5) showed average lipid in the range of $60-70 \%$ of DCW, however the DHA fraction of each isolate was highly variable. BhP22, GW11, GW12, GVK5, VSL3, VSL31, VSL32, CH4 showed lipid content between $76-80 \%$ of DCW, however the fraction of DHA was found to be variable among the isolates ranging from $23-40 \%$ of TFA. Based on the data obtained after total DCW, and Lipid, it was found that the best isolate among all those under study was BhP22 in terms of DHA yield, while GW11 showed highest lipid content (80.8\%) which is higher than any reported strain.

\section{Conclusion}

32 strains of Thraustochytrids were isolated from coast of Mumbai and Goa by using pine pollen baiting. Morphological evidences showed them to be of different types. Modified antibiotic concoction was found for the selective isolation of variety of strains that had slow growth rate. Isolates having faster growth rate were examined for their potential to produce omega 3 fatty acids and all strains showed presence of DHA. GW11 showed highest DHA of $1.97 \mathrm{~g} \mathrm{~L}^{-1}$ of under unoptimized condition. Further optimization of culture conditions could increase the DHA production. Also some strains can be exploited for pigments and enzyme production.

\section{Acknowledgements}

Authors acknowledge Department of Science and Technology, Govt of India New Delhi for funding this work.

\section{Conflict of Interest}

No Conflict of Interest declared

\section{References}

[1] Aki, T., Hachida, K., Yoshinaga, M., Katai, Y., Yamasaki, T., et al. (2003). Thraustochytrid as a potential source of carotenoids. Journal of the American Oil Chemists Society. 80 (8) 789-794.

[2] Bertozzini, E, Galluzzi, L, Penna, A, Magnani M., (2012) Application of the standard addition method for the absolute quantification of neutral lipids in microalgae using Nile red Journal of Microbiological Methods. 87: 17-23.

[3] Bhosale, R. A., Rajabhoj, M. P., Chaugule, B. B. (2010). Dunaliella salina Teod. as a Prominent Source of Eicosapentaenoic Acid. International Journal on Algae, 12(2): 185-189.

[4] Bongiorini, L., Pignataro, L. and Santangelo, G. (2004) Thraustochytrids (fungoid protists): an unexplored component of marine sediment microbiota. Sci Mar 68, 43-48.

[5] Burja,A. M., Armenta, R. E., Radianingtyas, H., Barrow, C.J., (2007) Evaluation of Fatty Acid Extraction. Methods for Thraustochytrium sp. ONC-T18. Agric. Food Chem., 55 (12), 4795-4801.

[6] Carvalho, A.P.; Malcata, F.X. (2005) Optimization of $\omega-3$ fatty acid production by microalgae: Crossover effects of $\mathrm{CO} 2$ and light intensity under batch and continuous cultivation modes. Mar. Biotechnol. 7, 381-388.

[7] Dratz, E.A., Deese, A.J., (1986). The role of docosahexaenoic acid in biological membranes: examples from photoreceptors and model membrane bilayers. In: Simopoulos, A.P., Kifer, R.R., Martin, R.E. (Eds.), Health effects of polyunsaturated fatty acids in seafoods. Academic Press, Orlando, FL. 319-330.

[8] Fan, K. W., Jiang, Y., Ho, L. L.K., and Chen, F., (2009) Differentiation in Fatty Acid Profiles of Pigmented and Nonpigmented Aurantiochytrium Isolated from Hong Kong Mangroves J. Agric. Food Chem. 57, 6334-6341.

[9] Hong, W.K., Rairakhwada, D., Seo, P,S., Park, S.Y., Hur, B.K., Kim, C.H,, Seo, J.W., (2011) Production of Lipids Containing High Levels of Docosahexaenoic Acid by a Newly Isolated Microalga, Aurantiochytrium sp. KRS101 Appl Biochem Biotechnol. 164:1468-1480.

[10] Horrocks, L. A., Yeo, Y.K., (1999) Health benefits of docosahexaenoic acid (DHA) Pharmacol Res., 40 (3):211-25.

[11] Jain, R., Raghukumar, S., (2005) Extracellular polysaccharide production by Thraustochytrid protists, Mar Biotech. 7 (3):184-92.

[12] Kris-Etherton P.M., Innis S., (2007) Position of the American Dietetic Association and Dietitians of Canada: dietary fatty acids. J Am diet Assoc. 107(9):1599-611.

[13] Leano EM, Gapasin R.S.J., Polohan B, Vrijmoed L.L.P., (2001) Growth and Fatty acid production of Thraustochytrids from Panay Mangroves, Phillipines. Fungal diversity.

[14] Nakahara, T., Yakochi, T., Higashihara, S., Tanaki, T., Yaguchi, T., Honda, D., (1996). Production of docosahexaenoic and docosapentaenoic acids by Schizochytrium sp. isolated from Yap Island. J. Am. Oil. Chem. Soc. 73 (11), 1421-1426.

[15] Raghukumar, S., (2002) Ecology of the marine protists, the Labyrinthulomycetes (Thraustochytrids and Labyrinthulids) Europ. J. Protistol. 38, 127-145.

[16] Taoka Y1, Nagano N, Okita Y, Izumida H, Sugimoto S, Hayashi M. (2010) Use of an antifungal drug, amphotericin B for isolation of thraustochytrids. J Biosci Bioeng. 110 (6):720-3.

[17] Yaguchi, T., S. Tanaka, T. Yokochi, T. Nakahara, and T. Higashihara. (1997). Production of high yields of docosahexaenoic acid by Schizochytrium sp. strain SR21. JAOCS (J. Assoc. Oil Chem. Soc.) 74: 1431-1434.

[18] http://www.mangroves.godrej.com/MangrovesinMumbai.htm 